\title{
Antiproliferative and Proapoptotic Effects of Tocopherol and Tocol on Activated Hepatic Stellate Cells
}

\author{
Noriko YAMAGUCHI ${ }^{1}$, Yoshihiro MEZAKI ${ }^{1}$, Mitsutaka MIURA $^{1}$, Katsuyuki IMAI ${ }^{1}$, \\ Mayako MORII ${ }^{2}$, Tatsuzo HeBIGUCHI ${ }^{2}$ and Kiwamu YoshIKAWA ${ }^{1}$ \\ ${ }^{1}$ Department of Cell Biology and Morphology, and ${ }^{2}$ Department of Pediatric Surgery, \\ Akita University Graduate School of Medicine, Akita 010-8543, Japan
}

(Received February 23, 2011)

\begin{abstract}
Summary Activated hepatic stellate cells (HSCs) play crucial roles in liver fibrosis. In the course of liver injury, HSCs, which reside in perisinusoidal spaces and lose lipid droplets, morphologically change into a myofibroblastic phenotype and acquire an increased proliferation activity in what is known as the activated state. We have investigated therapeutic strategies for liver fibrosis by promoting spontaneous reversion or inducing apoptosis in activated HSCs. Vitamin E consists of four tocopherols and four tocotrienols, all of which are well-known antioxidants. In this study, the antiproliferative and proapoptotic effects of a tocol, which lacks methyl groups attached to the chromanol ring, and four tocopherols were investigated using activated HSCs. $\delta$-Tocopherol and tocol exhibited relatively high proliferation inhibitory and proapoptotic abilities. However, they did not show proliferation inhibition ability on primary hepatocytes or HepG2 cells. Significant cell detachment was also observed in $\delta$-tocopherol- and tocol-treated HSCs. Decreased protein expressions of $\alpha$ smooth muscle actin and $\beta 1$ integrin were observed in a dose-dependent manner. These results indicate that $\delta$-tocopherol and tocol induce anoikis in activated HSCs.
\end{abstract}

Key Words tocopherol, tocol, hepatic stellate cells, apoptosis, anoikis

Vitamin $\mathrm{E}$ is an essential nutrient and a well-known lipid-soluble antioxidant. It consists of eight compounds, $\alpha-, \beta-, \gamma_{-}$, and $\delta$-tocopherol and $\alpha-, \beta-, \gamma_{-}$, and $\delta$-tocotrienol. Among these, $\alpha$-tocopherol is the most biologically active in scavenging free radicals, most abundant in human plasma, and most extensively studied compound (1). However, recent experiments have demonstrated that vitamin $\mathrm{E}$ also exhibits non-antioxidant activities, for example, inhibition of platelet aggregation (2); lowering of the serum cholesterol level (3); and inhibition of proliferation of smooth muscle cells (4), macrophages (5), and cancer cells $(6-8)$. Furthermore, vitamin $\mathrm{E}$ induces apoptosis in various cancer cells $(7,9)$.

Oxidative stress is implicated in various types of liver diseases and is considered to be the primary cause of alcoholic liver disease, non-alcoholic steatohepatitis, non-alcoholic fatty liver diseases, and viral hepatitis $(10,11)$. Hepatic stellate cells (HSCs), also known as hepatic lipocytes, fat-storing cells, or Ito cells, are activated under oxidative stress conditions. HSCs reside in the perisinusoidal spaces between hepatocytes and sinusoidal endothelial cells, and store vitamin A as retinyl esters in their cytoplasmic lipid droplets. Reactive oxygen species stimulate HSC proliferation and induce HSC transdifferentiation into myofibroblastic cells, which express $\alpha$-smooth muscle actin ( $\alpha$-SMA) and synthesize a significant amount of extracellular matrix components, particularly fibrillar collagens (12-14).

E-mail: noriko-y@gipc.akita-u.ac.jp
Therefore, they have been recognized as a potential therapeutic target for liver fibrosis (15). HSC activation can be observed and reproduced through isolation of HSCs by culturing on plastic plates. HSCs activated in vitro also acquire increased proliferative activity and myofibroblastic characteristics, such as $\alpha$-SMA expression and increased collagen synthesis $(16,17)$.

These findings prompted us to investigate the effect of vitamin $\mathrm{E}$ on activated HSC proliferation and $\alpha$-SMA expression. Because $\alpha$-tocopherol has been extensively studied, the biological activities of $\beta$-, $\gamma$-, and $\delta$-tocopherol, and tocol, which unlike $\alpha$-tocopherol, lacks a methyl group attached to the chromanol ring, were investigated. Tocol is not a natural substance but a chemically synthesized compound; to our knowledge, there has been no research on its biological activity. Because the antioxidant activity of tocol is the lowest among the compounds stated above (18), we considered it to be a useful compound in evaluating whether the antiproliferative effect of vitamin $\mathrm{E}$ is related to its antioxidant activity. In this study, $\delta$-tocopherol and tocol exhibited a relatively strong antiproliferative activity and induced anoikis, a specific type of apoptosis, in activated HSCs.

\section{MATERIALS AND METHODS}

Chemicals. Analytical grade $d$ - $\alpha$-tocopherol, $d$ - $\beta$-tocopherol, $d-\gamma$-tocopherol, $d$ - $\delta$-tocopherol, and $d \mathrm{l}$-tocol (3,4-dihydro-2-methyl-2-(4,8,12-trimethyltridecyl)-2H1-benzopyran-6-ol) were supplied by Eisai Co. Ltd. (Tokyo, Japan). 
Isolation and culture of HSCs and hepatocytes. Hepatic parenchymal and non-parenchymal cells were prepared from 6- to 7-wk-old male Wistar rats using the collagenase (Wako Pure Chemical Industries, Ltd., Osaka, Japan) perfusion method $(19,20)$. After separation of hepatocytes by low-speed centrifugation for $3 \mathrm{~min}$ at $50 \times g$, the supernatant containing stellate cells was further centrifuged in a Percoll (GE Healthcare Bio-Sciences AB, Uppsala, Sweden) density gradient to isolate stellate cells (21). Primary stellate cells were cultured in plastic dishes using DMEM (Invitrogen/Gibco, Grand Island, NY) containing 10\% fetal bovine serum (FBS, Equitech-Bio Inc., Kerrville, TX) and penicillin-streptomycin (Invitrogen/Gibco). After the cells reached confluence, they were treated with trypsin and subsequently maintained as described above. HSCs at passage 1-2 were used for experiments. Primary rat hepatocytes were cultured in collagen I- (rat tail tendon collagen, Beckton Dickinson, Franklin Lakes, NJ) coated dishes using DMEM containing 10\% FBS, penicillinstreptomycin, $2.5 \mu \mathrm{g} / \mathrm{mL}$ of bovine insulin (Sigma-Aldrich, St. Louis, MO), and $7 \times 10^{-5} \mathrm{M}$ of hydrocortisone hemisuccinate (Sigma-Aldrich) $(22,23)$. HSC-T6 cells, an immortalized rat hepatic stellate cell line (24), were generously provided by Dr. S. L. Friedman of the Mount Sinai School of Medicine. We cultured HSC-T6 cells and a hepatocellular liver carcinoma cell line, HepG2 cells, under the same conditions as the primary HSCs. The animal experimentation protocol for preparation of rat HSCs and hepatocytes was approved by the Animal Research Committee of Akita University and the subsequent animal experiments adhered to the Guidelines for Animal Experimentation of the university.

Proliferation assay. HSCs, HSC-T6, and HepG2 cells were subcultured in 24 -well plates $\left(1 \times 10^{4}\right.$ cells/well $)$ and maintained until subconfluent. Hepatocytes were seeded in collagen I-coated 24 -well plates $\left(1.25 \times 10^{5}\right.$ cells/well) and exposed to the tocopherols and tocol for $24 \mathrm{~h}$ following isolation. Stock solutions of $\alpha-, \beta-, \gamma$, and $\delta$-tocopherol, and tocol (100 mM) were prepared by dissolving them in $100 \%$ ethyl alcohol (Wako Pure Chemical Industries, Ltd.). The culture medium was replaced with DMEM containing 10\% FBS with various concentrations of $\alpha-, \beta-, \gamma-$, and $\delta$-tocopherol, and tocol. Cells were further incubated for $48 \mathrm{~h}$ at $37^{\circ} \mathrm{C}$. After treatment, cell numbers in each well were quantified using an MTT (methylthiazolyldiphenyl-tetrazolium bromide, Sigma-Aldrich) assay (25). Proliferation was expressed as a percentage of the ethyl alcohol (0.1\%)-treated control.

Cellular concentrations of $\alpha-, \beta-, \gamma-$, and $\delta$-tocopherol, and tocol. Cells were incubated with $100 \mu \mathrm{M}$ of $\alpha-, \beta-$, $\gamma$-, and $\delta$-tocopherol, and tocol for 6,24 , and $48 \mathrm{~h}$ at $37^{\circ} \mathrm{C}$. The HSC-T6 cells were incubated with $100 \mu \mathrm{M}$ of tocol for $6,11.5$, and $24 \mathrm{~h}$. At the end of incubation, the cells were harvested by trypsinization and washed with PBS. Finally, cell pellets were resuspended in distilled water, and the concentrations of $\alpha-, \beta-, \gamma_{-}$, and $\delta$ tocopherol, and tocol were determined. The four tocopherol isomers and tocol were extracted with organic solvents and analyzed by high-performance liquid chromatography (HPLC). Two milliliters of ethanol and $8 \mathrm{~mL}$ of $n$-hexane were mixed with $1 \mathrm{~mL}$ of cell suspension thoroughly in that order. The organic layer was recovered by centrifugation and the extracts were evaporated to dryness, and resolved in $200 \mu \mathrm{L}$ of the eluent ( $5 \%$ tert-butyl methyl ether, $0.04 \%$ ethanol, and 25\% benzene in $n$-hexane) of HPLC. The HPLC system (LaChrom Elite Pump L-2130, Hitachi High-Technologies, Tokyo, Japan), equipped with a $6 \mathrm{~mm} \times 150 \mathrm{~mm}$ column of 3- $\mu \mathrm{m}$ silica gel (YMC-Pack-A-012 S-3 SIL, Yamamura Chemical Laboratories, Kyoto, Japan) with a $4 \mathrm{~mm} \times 50 \mathrm{~mm}$ precolumn and a flow rate of $2 \mathrm{~mL} / \mathrm{min}$, was used. Absorbance was monitored using a UV-visible detector (LaChrom Elite Diode Array Detector L2450, Hitachi High-Technologies). The four tocopherol isomers and tocol were identified based on the retention time and absorbance at 292-298 $\mathrm{nm}$ in comparison with the standard.

Identification of apoptotic cells by annexin $V$ binding. HSCs were plated onto 60-mm dishes and cultured in DMEM containing 10\% FBS. The four tocopherol isomers and tocol were added at a final concentration of 50 or $100 \mu \mathrm{M}$ to fresh DMEM containing 10\% FBS and cultured continuously for 24 or $48 \mathrm{~h}$. Ethyl alcohol $(0.1 \%)$ was added to the control group. For the positive control, rat HSCs were cultured under serum-starved conditions for $24 \mathrm{~h}$ and incubated with $10 \mu \mathrm{M}$ of $15-$ deoxy- $\Delta^{12,14}$-prostaglandin J2 (15d-PGJ2, Cayman Chemical, Ann Arbor, MI) for an additional $24 \mathrm{~h}$ in the presence or absence of 10\% FBS (26). Cells were harvested by trypsinization and stained with annexin $\mathrm{V}$ allophycocyanin conjugates using the Vybrant Apoptosis Assay Kit to detect apoptotic cells (Molecular Probes, Eugene, OR), and SYTOX Green was used to detect cellular DNA, according to the manufacturer's protocol. The stained cells were analyzed on a MoFlo cell sorter (Dako Cytomation, Glostrup, Denmark).

TUNEL labeling and fluorescence microscopy analysis. To confirm the induction of apoptosis, we performed TUNEL labeling on $\delta$-tocopherol- and tocol-treated HSCs. In brief, HSCs were plated onto 35-mm collagencoated glass bottom culture dishes (Mat Tek Corporation, Ashland, MA). Cells were treated with $100 \mu \mathrm{M}$ of $\delta$-tocopherol for $48 \mathrm{~h}$ or with 50 and $100 \mu \mathrm{M}$ of tocol for 24 or $48 \mathrm{~h}$ in DMEM containing 10\% FBS. After incubation, cells were washed a couple of times with PBS and fixed with 2\% paraformaldehyde (TAAB Lab., Berkshire, England) for $4 \mathrm{~min}$ at room temperature. Before TUNEL labeling, cells were permeabilized by incubation with $0.2 \%$ Triton $\mathrm{X}-100$ solution for $5 \mathrm{~min}$ at room temperature. TUNEL labeling was performed using the DeadEnd Fluorometric TUNEL System (Promega, Madison, WI) according to the manufacturer's protocol. Nuclei were counterstained with $0.5 \mu \mathrm{M}$ of TO-PRO-3 iodide (Molecular Probes/Invitrogen, Eugene, OR). Images were acquired using the confocal microscope LSM 510 (Carl Zeiss, Jena, Germany).

Western blot analysis of $\alpha$-SMA and $\beta 1$ integrin. HSCs were incubated with different concentrations of tocoph- 
erols and tocol for 96 and $48 \mathrm{~h}$, respectively. Then, cells were washed with cold PBS and harvested in RIPA buffer (Sigma-Aldrich) and a protease inhibitor cocktail (Sigma-Aldrich). Protein concentrations of cell lysates were quantified using the Micro BCA Protein Assay Reagent Kit (Pierce, Rockford, IL); $10 \mu \mathrm{g}$ of protein for $\alpha$-SMA and $20 \mu \mathrm{g}$ of protein for $\beta 1$ integrin were separated from each sample by SDS-polyacrylamide gel electrophoresis (SDS-PAGE). SDS-PAGE was performed on a $10 \%$ gel for $\alpha$-SMA and a $7.5 \%$ gel for $\beta 1$ integrin. For immunoblot analysis, proteins were electrophoretically transferred onto a nitrocellulose membrane (BA83; Schleicher \& Schuell, Dassel, Germany) (27). The membrane was blocked with 5\% skim milk/0.05 M Tris-HCl (pH 7.5) and $0.15 \mathrm{M} \mathrm{NaCl}$ buffer containing $0.1 \%$ Tween 20 (Calbiochem, La Jolla, CA) for $1 \mathrm{~h}$ at room temperature, and incubated overnight at $4^{\circ} \mathrm{C}$ with an anti- $\alpha$-SMA mouse monoclonal antibody (Progen, Heidelberg, Germany). Then, it was incubated with an alkaline phosphatase-conjugated anti-mouse IgG antibody (Promega) and visualized by incubation with the AP Conjugate Substrate Kit (Bio-Rad Laboratories, Hercules, CA). To detect $\beta 1$ integrin, the membrane was incubated with an anti- $\beta 1$ integrin antibody (Santa Cruz Biotechnology Inc., Santa Cruz, CA) at room temperature for $1 \mathrm{~h}$, followed by incubation with peroxidase-conjugated anti-rabbit IgG (Jackson ImmunoResearch Lab. Inc., West Grove, PA). $\beta 1$ integrin was detected by enhanced chemiluminescence (GE Healthcare Bio-Sciences, Little Chalfont, UK), and the signals were recorded on an X-ray film (Fujifilm, Tokyo, Japan).

Statistical analysis. Data are presented as means \pm standard deviation (SD). Statistical differences from the control group were calculated by the one-way ANOVA test, followed by the Scheffe's test. p-values below 0.01 were regarded as significant.

\section{RESULTS}

Comparative inhibition of HSC proliferation by the four tocopherol isomers and tocol

Chemical structures of the four tocopherol isomers and tocol used in this study are shown in Fig. 1e. First, the effects of the four tocopherol isomers and tocol on proliferation of culture-activated HSCs were examined. After 48-h incubation of HSCs with various tocopherol and tocol concentrations, the number of live cells was estimated and plotted as a percentage of the control group. $\delta$-Tocopherol and tocol showed significant inhibitory activities, i.e., $>50 \%$ reduction in HSC proliferation at a concentration of $50 \mu \mathrm{M}$ (Fig. 1a). $\alpha$-Tocopherol inhibited cell proliferation moderately (30\%), whereas $\beta$-tocopherol inhibited proliferation by $12 \%$ at a concentration of $50 \mu \mathrm{M}$. However, treatment with $100 \mu \mathrm{M}$ of $\alpha$ - and $\beta$-tocopherol showed $41 \%$ and $48 \%$ growth inhibition, respectively. In contrast, hardly any inhibition was observed in the $\gamma$-tocopherol-treated group at concentrations of $10-100 \mu \mathrm{M}$ (Fig. 1a). These results indicate that the antiproliferative effect of the four tocopherols and tocol on HSCs is in the order tocol $=\delta$-tocopherol $>\alpha$-tocopherol $>\beta$-tocopherol $>$ $\gamma$-tocopherol. The antiproliferative activities were further investigated using HSC-T6 cells, an immortalized rat liver stellate cell line possessing the characteristics of activated HSCs (24). Tocol exhibited a strong cytotoxic activity against HSC-T6 cells, and at concentrations of 50 and $100 \mu \mathrm{M}$, it significantly reduced the number of live cells to $4 \%$ of the control group (Fig. 1b). Treatment with $100 \mu \mathrm{M}$ of $\delta$-tocopherol showed significant cell proliferation inhibition by $47 \%$, while no proliferation inhibition was observed in the $\alpha-, \beta$-, and $\gamma$-tocopheroltreated groups (Fig. 1b). Rather, $\gamma$-tocopherol stimulated HSC-T6 proliferation $(p<0.01$ at $50 \mu \mathrm{M}, p<0.001$ at $100 \mu \mathrm{M})$.

Next, we examined the antiproliferative activities using rat hepatocytes and the hepatocellular carcinoma cell line, HepG2. None of the four tocopherol isomers showed any inhibition of hepatocyte proliferation at concentrations of $10-100 \mu \mathrm{M}$, whereas $50 \mu \mathrm{M}$ of tocol slightly stimulated proliferation $(p<0.01$, Fig. 1c). Furthermore, the antiproliferative effects of the four tocopherol isomers and tocol were not observed in HepG2 cells, while treatment with $100 \mu \mathrm{M}$ of $\alpha$-tocopherol significantly stimulated cell proliferation by $40 \%$ (Fig. 1d).

Cellular concentrations of the four tocopherol isomers and tocol

To elucidate the effects of the four tocopherol isomers and tocol on cell proliferation, their cellular concentrations at various incubation times were measured. A time-responsive increase in the cellular concentrations of the four tocopherol isomers in HSCs, HSC-T6 cells, hepatocytes, and HepG2 cells was observed over a 48-h period (Fig. 2). Because HSC-T6 cells treated with tocol for $48 \mathrm{~h}$ were detached almost completely from culture dishes, we could not measure the cellular concentration of tocol. The cellular concentration of tocol reached a maximum at $24 \mathrm{~h}$ in heptocytes, while it increased over $48 \mathrm{~h}$ in HSCs and HepG2 cells. Furthermore, the cellular concentration of tocol in HSCs and HSC-T6 cells at $24 \mathrm{~h}$ was approximately twice that in hepatocytes and HepG2 cells. Distinct differences were observed between the cellular concentrations of the four tocopherol isomers and tocol. During the incubation period, these concentrations in all cells studied, except hepatocytes, were in the order tocol $>\delta$-tocopherol $>(\gamma$-tocopherol, $\beta$-tocopherol) $>\alpha$-tocopherol. In hepatocytes, the cellular concentration of $\gamma$-tocopherol was almost same as that of $\alpha$-tocopherol rather than $\beta$-tocopherol (Fig. 2c). These results indicate that the cellular concentrations of the four tocopherol isomers and tocol demonstrate an inverse correlation with the hydrophobicity of their chromanol rings (Fig. 1e).

Apoptosis induction activities of $\delta$-tocopherol and tocol demonstrated by flow cytometric analyses and TUNEL assay

We examined whether proliferation inhibition induced by tocopherols and tocol was the result of apoptosis. To estimate apoptotic induction in HSCs, we first employed FACS analysis. The results of apoptotic cell detection following incubation with the four tocopherol isomers and tocol are shown in Fig. 3a. Approximately 
(a)

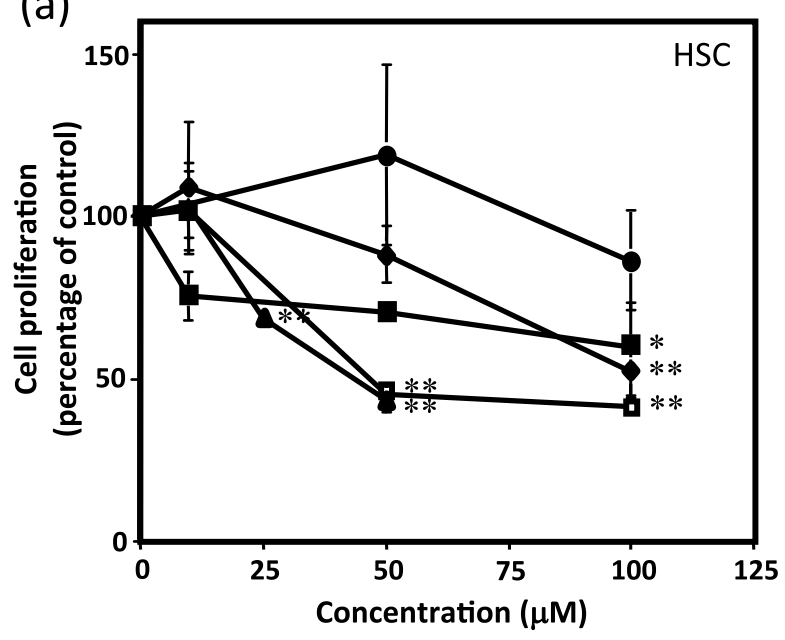

(c)

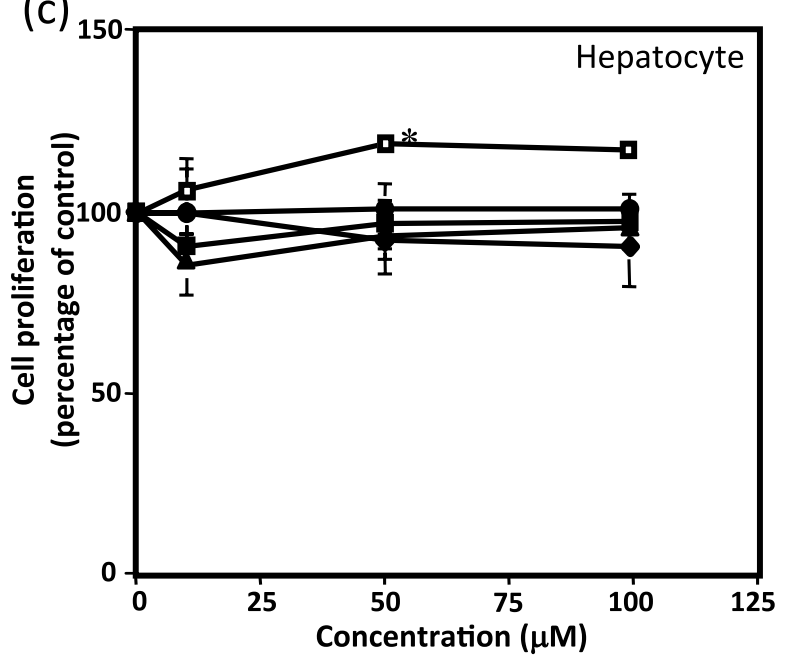

(b)
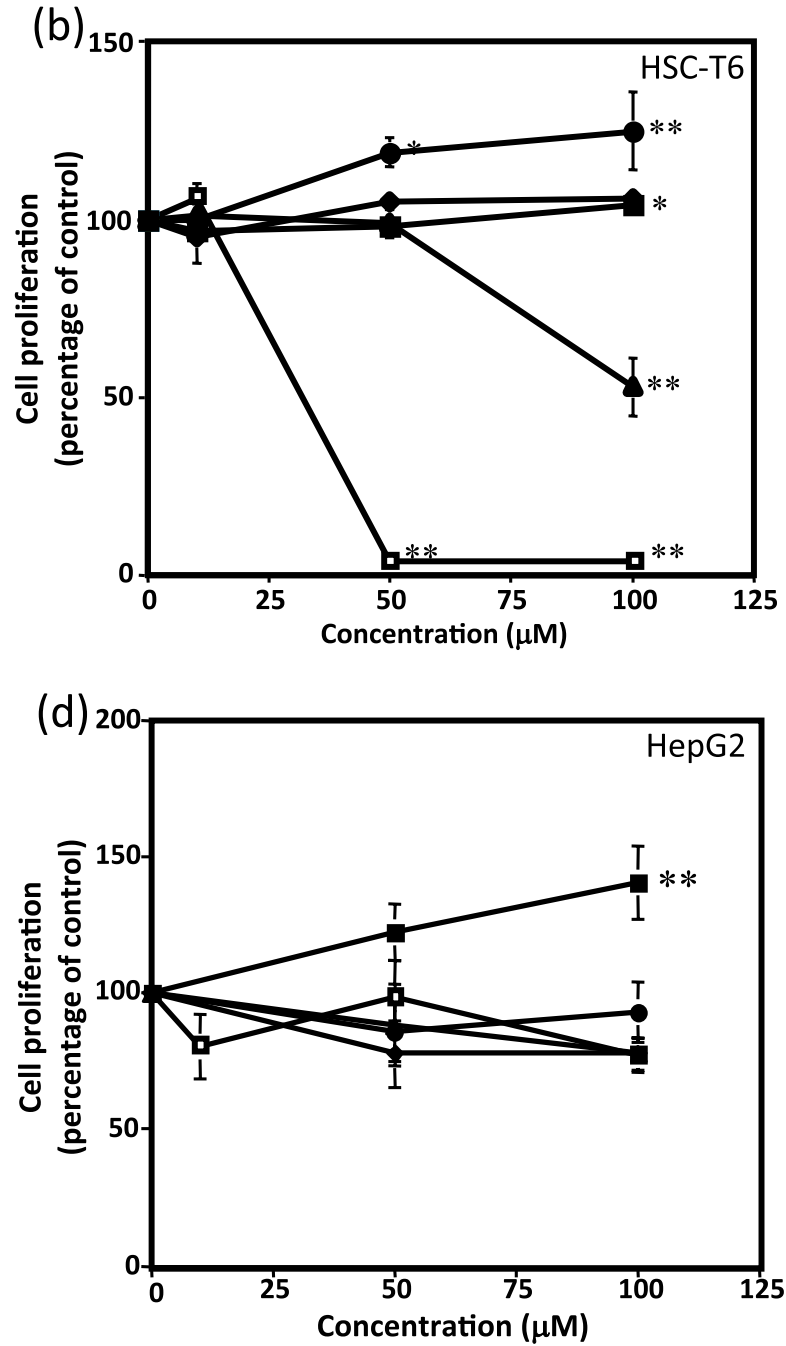

(e)
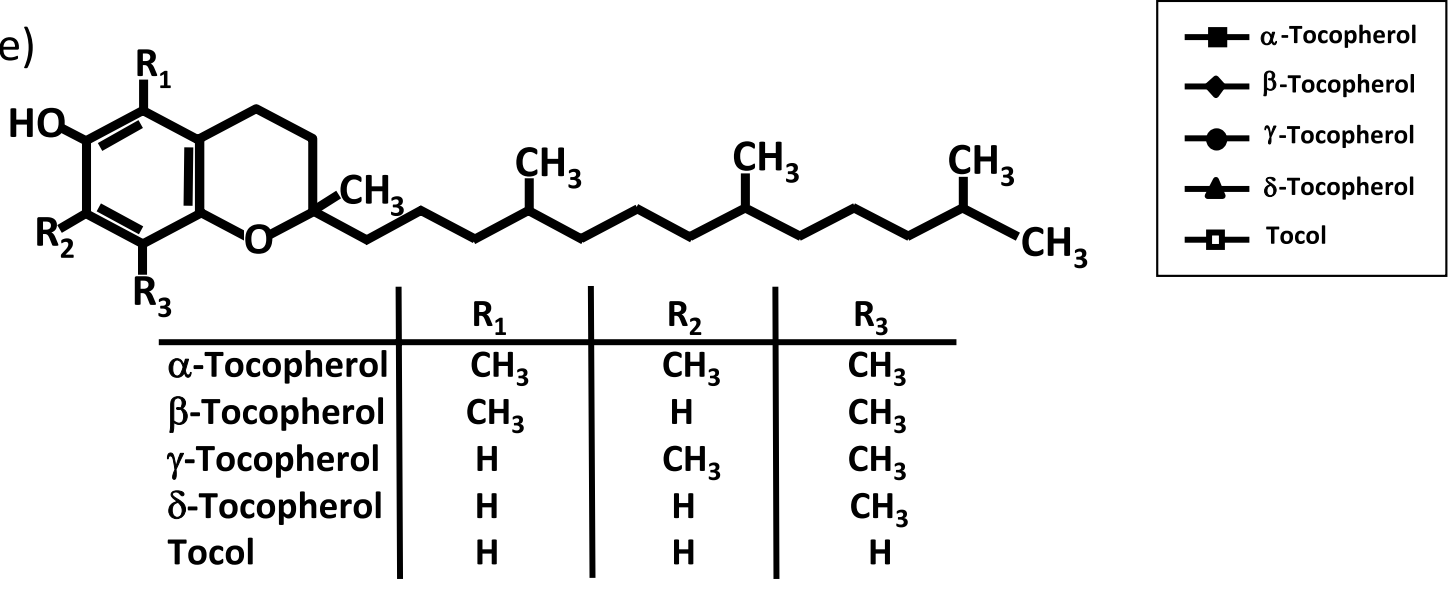

\begin{tabular}{l|l|l|l} 
& $\mathrm{R}_{1}$ & $\mathrm{R}_{2}$ & $\mathrm{R}_{3}$ \\
\hline$\alpha$-Tocopherol & $\mathrm{CH}_{3}$ & $\mathrm{CH}_{3}$ & $\mathrm{CH}_{3}$ \\
$\beta$-Tocopherol & $\mathrm{CH}_{3}$ & $\mathbf{H}$ & $\mathrm{CH}_{3}$ \\
$\gamma$-Tocopherol & $\mathbf{H}$ & $\mathrm{CH}_{3}$ & $\mathrm{CH}_{3}$ \\
$\delta$-Tocopherol & $\mathbf{H}$ & $\mathbf{H}$ & $\mathrm{CH}_{3}$ \\
Tocol & $\mathbf{H}$ & $\mathbf{H}$ & $\mathbf{H}$
\end{tabular}

Fig. 1. Effect of tocopherols and tocol on the proliferation of culture-activated HSCs (a), HSC-T6 (b), hepatocytes (c), and HepG2 (d). Cells were incubated with different concentrations of the four tocopherol isomers and tocol $(0,10,50$, $100 \mu \mathrm{M}$ ) for $48 \mathrm{~h}$ in the presence of $10 \% \mathrm{FBS}$. After incubation, the number of live cells was measured using MTT assay as described in "Materials and Methods." Data are calculated in comparison with the respective solvent ethanol-treated control cells $(100 \%)$. Results are shown as means \pm SD of representative experiments performed at least 3 times in sextuplicate. Significantly different from the control, ${ }^{*} p<0.01$ and ${ }^{* *} p<0.001$. Chemical structures of $\alpha$-, $\beta$-, $\gamma$-, and $\delta$-tocopherol, and tocol (e). Tocol has the fundamental structure with no methyl group attached to the chromanol ring.

$5 \%$ of the total cells measured were identified as apoptotic cells in the control group containing $0.1 \%$ ethanol. After 24-h serum starvation, HSCs were incubated with $10 \mu \mathrm{M}$ of $15 \mathrm{~d}-\mathrm{PGJ} 2$, an inducer of apoptosis in
HSCs, for $24 \mathrm{~h}$ in the absence of FBS. The number of apoptotic cells in the 15d-PGJ2-treated group increased to $42.65 \pm 9.77 \%$. In the absence of pretreatment with serum starvation, treatment with $100 \mu \mathrm{M}$ of $\delta$-tocopherol 
(a)

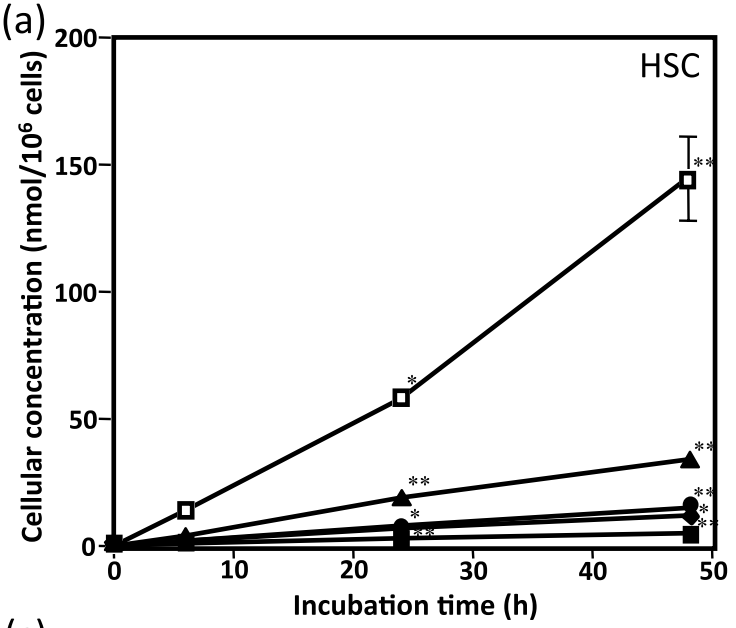

(c)

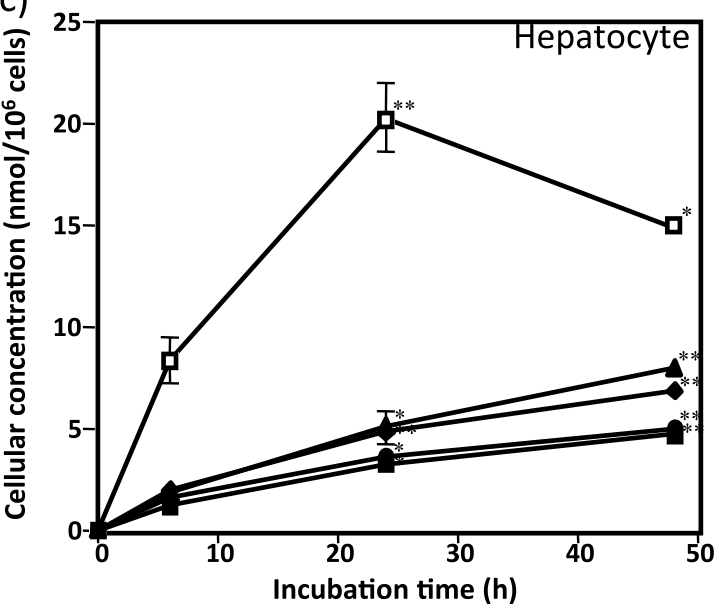

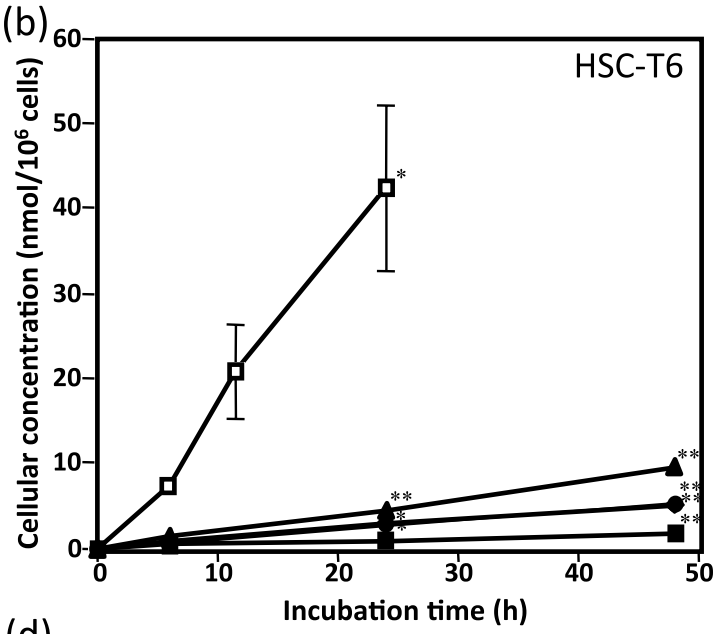

(d)

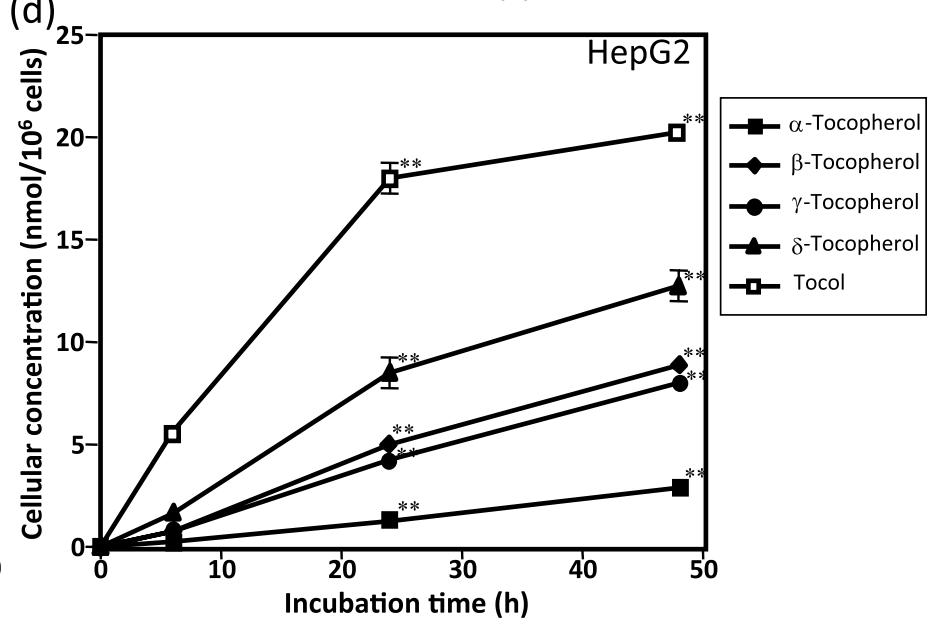

Fig. 2. Cellular concentrations of the four tocopherol isomers and tocol in HSCs (a), HSC-T6 (b), hepatocytes (c), and HepG2 (d). Cells were incubated with $100 \mu \mathrm{M}$ of $\alpha-, \beta-, \gamma-, \delta$-tocopherol, and tocol for 6,24 , and $48 \mathrm{~h}$ at $37^{\circ} \mathrm{C}$. The HSCT6 cells were incubated with $100 \mu \mathrm{M}$ of tocol for $6,11.5$, and $24 \mathrm{~h}$. After incubation, the cells were harvested by trypsinization, and tocopherol and tocol concentrations were determined by HPLC. Cellular concentrations are expressed in nanomoles per $10^{6}$ cells. Results are shown as means \pm SD of three experiments. Significantly different from the control $(0 \mathrm{~h}),{ }^{*} p<0.01$ and ${ }^{* *} p<0.001$.

increased the number of apoptotic cells slightly by $11.49 \pm 1.93 \%$ after 48 -h incubation (Fig. 3a). In contrast, tocol treatment significantly increased the number of apoptotic cells in a dose- and time-dependent manner. When HSCs were incubated with $100 \mu \mathrm{M}$ of tocol for $24 \mathrm{~h}$, the number of apoptotic cells increased to $28.03 \pm 6.73 \%$, which was comparable to treatment with $50 \mu \mathrm{M}$ of tocol for $48 \mathrm{~h}(27.79 \pm 5.19 \%)$, and was almost twice that of treatment with $50 \mu \mathrm{M}$ of tocol for $24 \mathrm{~h}(14.63 \pm 5.03 \%)$ (Fig. 3a). Treatment with $100 \mu \mathrm{M}$ of tocol for $48 \mathrm{~h}$ resulted in $46.46 \pm 1.54 \%$ of apoptotic cells, corresponding to the positive control 15d-PGJ2. However, treatment with $100 \mu \mathrm{M}$ of $\alpha$-, $\beta$-, and $\gamma$-tocopherol did not result in a significant change in apoptosis induction compared with the control. Flow cytometric analysis clearly demonstrated the apoptosisinducing activity of $\delta$-tocopherol and tocol.

Next, confirmation of apoptosis induction in HSCs was attempted using a TUNEL assay. TUNEL-positive cells were observed in the $100 \mu \mathrm{M}$ of $\delta$-tocopherol-, 50 and $100 \mu \mathrm{M}$ of tocol-, and 15d-PGJ2-treated groups (Fig. 3b). In the $100 \mu \mathrm{M}$ of tocol-treated cells, some nuclei were deformed and condensed. These cells showed significant features of advanced stage apoptosis. For confocal microscopy, we selected fields showing one or more TUNEL-positive cells.

$\delta$-Tocopherol and tocol treatments lead to cell detachment and anoikis

Striking morphological changes and cell detachment were observed after treatment with $100 \mu \mathrm{M}$ of $\delta$ tocopherol for $96 \mathrm{~h}$ and $100 \mu \mathrm{M}$ of tocol for $24 \mathrm{~h}$ (Fig. $4 \mathrm{a})$. Cell detachment was also observed in the $50 \mu \mathrm{M}$ of tocol-treated group (data not shown). The number of attached cells decreased in a dose-dependent manner. Compared to well-attached and flattened myofibroblastic cells observed in the control and $\alpha-, \beta$-, and $\gamma$ tocopherol-treated groups, cells in the $\delta$-tocopheroland tocol-treated groups showed morphological changes such as rounding and blebbing (Fig. 4a). In addition, cell shrinkage and thin process-like structures were prominent among the attached cells in the $\delta$ tocopherol- and tocol-treated groups. These observations indicate that $\delta$-tocopherol and tocol treatments lead to anoikis in HSCs. 
(a)

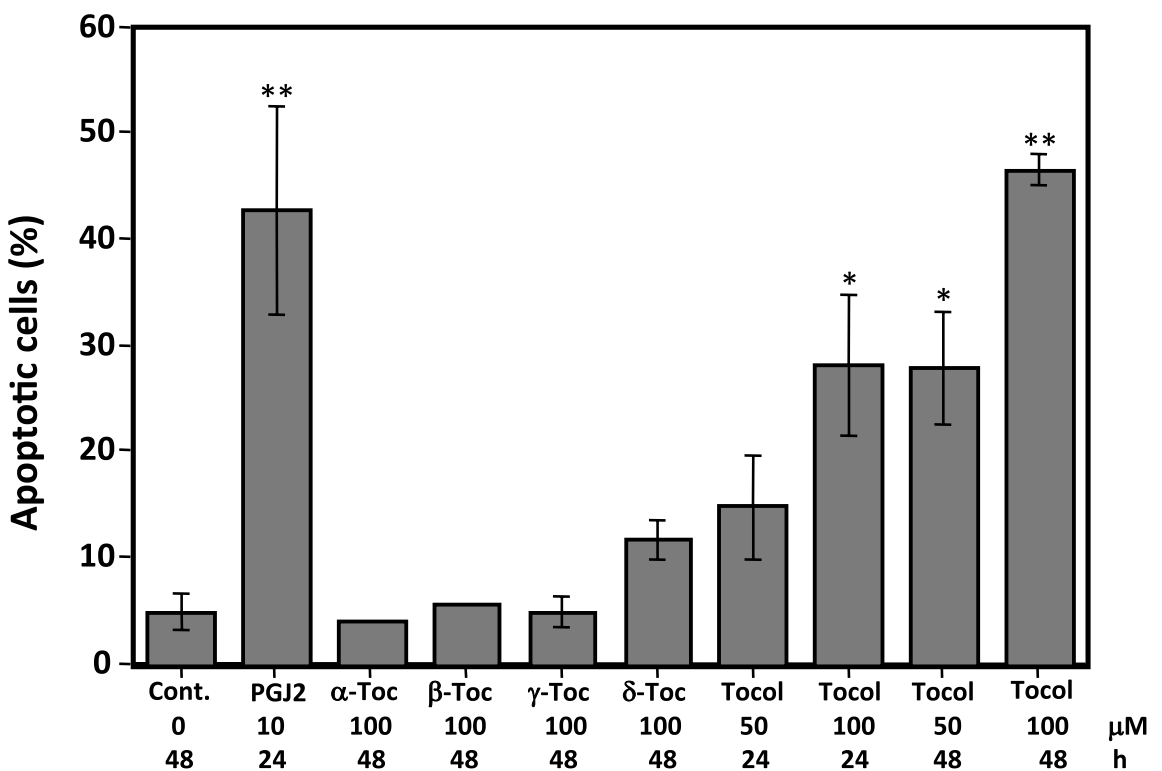

(b)

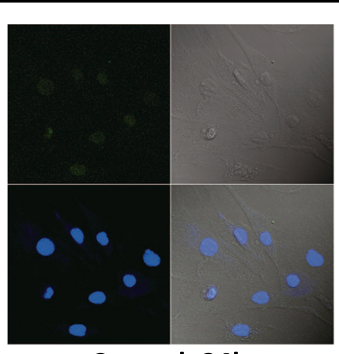

Control, 24h

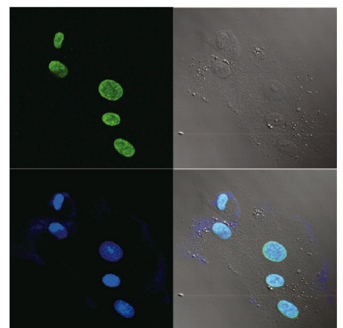

$50 \mu \mathrm{M}$ Tocol, 24h

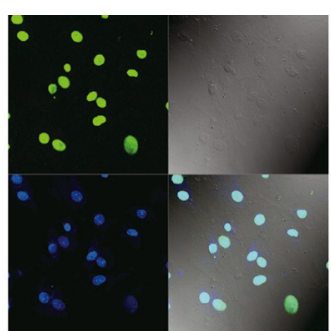

$10 \mu \mathrm{M}$ 15d-PGJ2, 24h

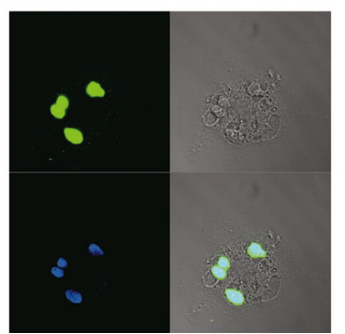

$100 \mu \mathrm{M}$ Tocol, $48 \mathrm{~h}$

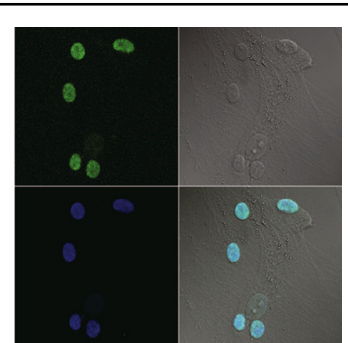

$100 \mu \mathrm{M} \delta$-Toc, $48 \mathrm{~h}$

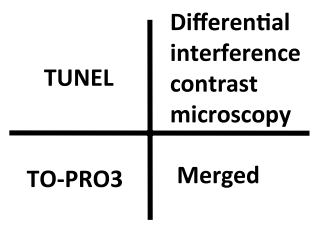

Fig. 3. Apoptosis detection in HSCs by flow cytometric analysis (a) and by the TUNEL assay (b). (a) HSCs were incubated with $100 \mu \mathrm{M}$ of $\alpha$-, $\beta$-, and $\gamma$-tocopherol (Toc) for $48 \mathrm{~h}$, and 50 and $100 \mu \mathrm{M}$ of tocol for 24 and $48 \mathrm{~h}$. After incubation, the cells were stained with allophycocyanin-labeled annexin V and SYTOX Green to detect nucleic acids. As a control, HSCs were incubated with the solvent ethyl alcohol $(0.1 \%)$. As a positive control, HSCs were incubated with $10 \mu \mathrm{M}$ of $15 \mathrm{~d}-\mathrm{PGJ} 2$ for $24 \mathrm{~h}$ in the absence of $10 \%$ FBS, immediately after 24-h serum starvation. Data are shown as means \pm SD of three independent experiments. Significantly different from the control, ${ }^{*} p<0.01$ and ${ }^{* *} p<0.001$. (b) HSCs were incubated with $100 \mu \mathrm{M}$ of $\delta$-tocopherol (Toc) for $96 \mathrm{~h}$, and 50 and $100 \mu \mathrm{M}$ of tocol for 24 and $48 \mathrm{~h}$ in the presence of $10 \%$ FBS. Apoptotic cells detected in the TUNEL assay are shown in green. Nuclear staining was performed with TO-PRO-3 and is shown in blue. Original magnification: $\times 400$.

To assess anoikis induction, expression of $\alpha$-SMA, a cytoskeletal marker protein for activated HSCs, was evaluated in cell lysates by western blot analysis. Because anoikis is considered to cause HSC death through detachment from the surrounding extracellular matrix, expression of $\beta 1$ integrin, a subunit of heterodimeric transmembrane proteins that functions as receptors for extracellular matrix proteins, was also evaluated. $\alpha$-SMA protein expression decreased in the $200 \mu \mathrm{M} \quad \gamma$-tocopherol-, $100 \mu \mathrm{M} \quad \delta$-tocopherol-, and $50 \mu \mathrm{M}$ tocol-treated groups compared with the control group (Fig. 4b). $\alpha$-SMA expression was barely detectable in the $200 \mu \mathrm{M} \delta$-tocopherol- and $100 \mu \mathrm{M}$ tocoltreated groups. Thus, $\gamma$-, and $\delta$-tocopherol, and tocol decreased $\alpha$-SMA expression in a dose-dependent manner. However, no significant change in $\alpha$-SMA expression was observed with $\alpha$ - or $\beta$-tocopherol treatments. $\beta 1$ Integrin expression decreased in the $200 \mu \mathrm{M} \delta$ tocopherol- and $100 \mu \mathrm{M}$ tocol-treated groups (Fig. 4b). $\delta$-Tocopherol and tocol decreased $\beta 1$ integrin expression in a dose-dependent manner similar to $\alpha$-SMA expression. In contrast, $\alpha-, \beta-$, and $\gamma$-tocopherol 
(a)

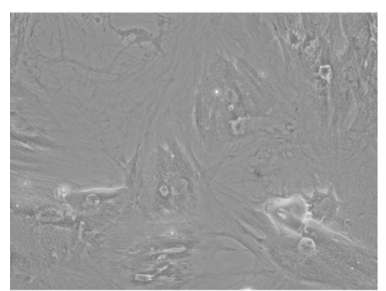

Control, 48h

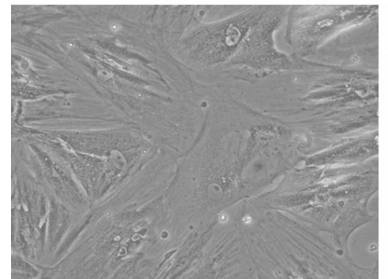

$100 \mu \mathrm{M} \gamma$-Toc, 48h

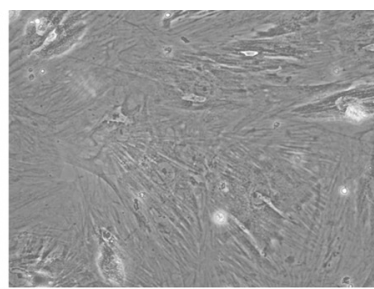

$100 \mu \mathrm{M} \alpha-T o c, 48 \mathrm{~h}$

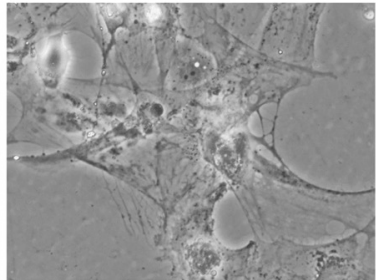

$100 \mu \mathrm{M} \delta$-Toc, 96h

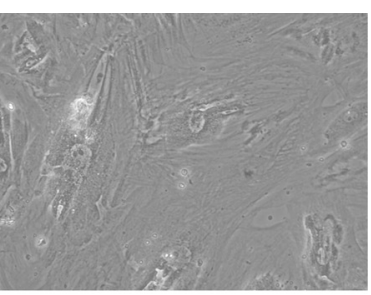

$100 \mu \mathrm{M} \beta$-Toc, $48 \mathrm{~h}$

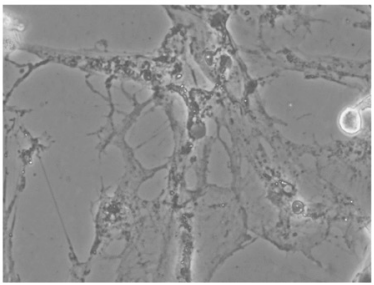

$100 \mu \mathrm{M}$ Tocol, 24h

(b)

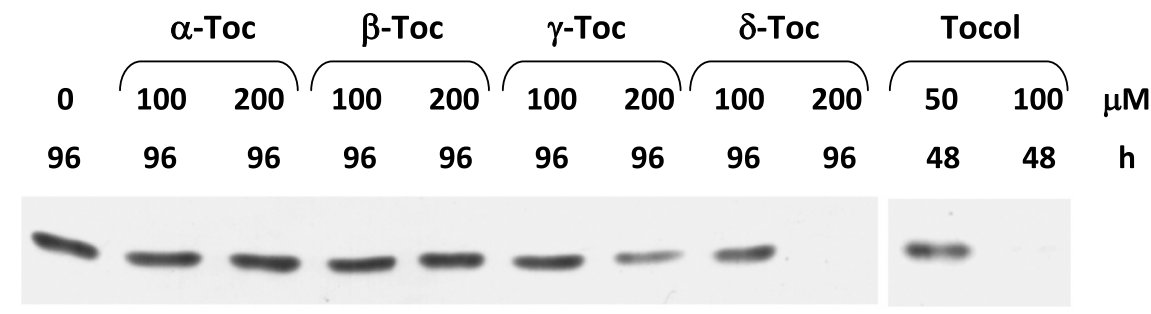

$\beta 1$ Integrin
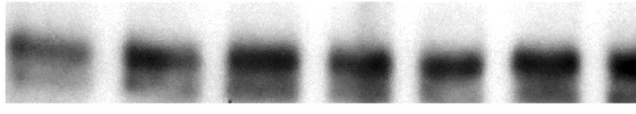

Fig. 4. Anoikis induction in HSCs by $\delta$-tocopherol and tocol. Morphological changes induced by $\delta$-tocopherol and tocol as shown by phase contrast photomicrographs (a). HSCs were incubated with $100 \mu \mathrm{M}$ of $\alpha$-, $\beta$-, and $\gamma$ - tocopherol (Toc) for $48 \mathrm{~h}, 100 \mu \mathrm{M}$ of $\delta$-tocopherol (Toc) for $96 \mathrm{~h}$, and $100 \mu \mathrm{M}$ of tocol for $24 \mathrm{~h}$. Note that only adherent cells are shown in the micrographs. Original magnification: $\times 100$. Expressions of $\alpha$-SMA and $\beta 1$ integrin were evaluated by western blot analysis (b). After treatment with 100 and $200 \mu \mathrm{M}$ of $\alpha-, \beta-, \gamma-, \delta$-tocopherol (Toc) for $96 \mathrm{~h}$ and with 50 and $100 \mu \mathrm{M}$ of tocol for $48 \mathrm{~h}$, HSC lysates were prepared with RIPA buffer. To detect $\alpha$-SMA and $\beta 1$ integrin, 10 and $20 \mu \mathrm{g}$ of protein from each cell lysate, respectively, was separated by SDS-PAGE. Specific antibodies recognized $42 \mathrm{kDa}$ of $\alpha$-SMA and $88 \mathrm{kDa}$ of $\beta 1$ integrin.

appeared to have no effect on $\beta 1$ integrin expression. Downregulation of the cytoskeletal protein $\alpha$-SMA and the cell adhesion molecule $\beta 1$ integrin correlated with the cell detachment activities of $\delta$-tocopherol and tocol.

\section{DISCUSSION}

We demonstrated that $\delta$-tocopherol and tocol show relatively strong inhibition of activated HSC proliferation. They exhibited $>50 \%$ inhibition and $\alpha$-tocopherol exhibited 30\% inhibition at a concentration of $50 \mu \mathrm{M}$. The normal average human serum concentration of $\alpha$ tocopherol is approximately $26.3 \mu \mathrm{M}(28)$; therefore, the $50 \mu \mathrm{M}$ concentration used in our experiment is representative of the physiological serum concentration that can be attained by supplementation. This is the first report describing the antiproliferative effect of tocol on proliferation of HSCs and HSC-T6 cells. Tocol is cytotoxic to HSC-T6 cells such that only $4 \%$ of the cells were viable after treatment at a concentration of 50 or
$100 \mu \mathrm{M}$. In contrast, $50 \mu \mathrm{M}$ of $\delta$-tocopherol inhibited proliferation of human mastocytoma cells (HMC-1) by $65 \%$ (29) and neoplastic mouse mammary epithelial cells by $50 \%$ (7). Accordingly, the inhibitory effect of $\delta$ tocopherol on HSC proliferation is comparable to that on proliferation of HMC-1 and neoplastic mouse mammary epithelial tumor cells.

The free radical scavenging reactivity at $\mathrm{pH} 4-8$ is in the order $\alpha$-tocopherol $>\beta$-tocopherol $=\gamma$-tocopherol $>$ $\delta$-tocopherol $>$ tocol $(18,30)$. Therefore, the antiproliferative effects of the four tocopherol isomers and tocol on HSCs and HSC-T6 cells appear to be different compared to their antioxidant activities. In contrast, $\delta$ tocopherol and tocol did not show any inhibition of proliferation of primary hepatocytes or HepG2 cells. Therefore, the antiproliferative activities of $\delta$-tocopherol and tocol seem to show cell selectivity.

The strong proliferation inhibition exhibited by $\delta$ tocopherol and tocol correlated well with their high cel- 
lular concentrations in HSCs. The tocol concentration in hepatocytes at $48 \mathrm{~h}$ was approximately one tenth of that in HSCs. However, no significant differences were observed among the cellular concentrations of $\delta$ tocopherol in HSC-T6 cells, hepatocytes, and HepG2 cells. Thus, it seems that there is no direct correlation between the cellular concentrations of the four tocopherol isomers and their antiproliferative activities, while the high tocol concentration in HSCs and HSC-T6 cells might partly contribute to their antiproliferative activities. The highest cellular concentration of $\delta$-tocopherol among the four tocopherol isomers was also observed in an in vitro supplementation study with mouse splenocytes (31), and human colonic carcinoma cells (Caco2) (32). This suggests that the molecular structure of the chromanol ring i.e., the number of methyl groups attached to the chromanol ring, is responsible for the uptake and efflux of the four tocopherol isomers and tocol. Therefore, a direct permeable mechanism through the lipid bilayer of the cell membrane may not be involved in this case. We speculate that there may be transporter molecule(s) that can discriminate the tocopherol isomers and tocol expressed on the HSC membrane. The scavenger receptor CD36 and low-density lipoprotein receptor are expressed by $\operatorname{HSCs}(33,34)$; however, no information is available about expression of scavenger receptor class B type 1 (35) or ATP-binding cassette transporter A1 (36) in HSCs. Therefore, the involvement of these molecules in vitamin E transportation in HSCs remains to be elucidated.

Apoptotic cells were detected in the tocol- and $\delta$ tocopherol-treated HSCs. Thus, the apoptosis induction ability of $\delta$-tocopherol and tocol may partly contribute to their antiproliferative activity in HSCs. As described previously, this is the first report demonstrating the antiproliferative and proapoptotic effects of tocol on HSCs. Apoptosis induced by $\delta$-tocopherol has been demonstrated using a macrophage cell line (5), as well as preneoplastic, neoplastic, and highly malignant mouse mammary epithelial cell lines (7). However, the proapoptotic effect of $\delta$-tocopherol on HSCs has not been investigated. Because $\alpha$-tocopherol did not show any proapoptotic activity in HSCs in the annexin $\mathrm{V}$ binding assay, the proapoptotic activities of $\delta$-tocopherol and tocol are considered to be independent of their antioxidant activities.

Although the apoptosis induction mechanism of $\delta$ tocopherol and tocol is still unknown, we found that $\delta$ tocopherol and tocol induced striking morphological changes in HSCs and caused cell detachment after treatment. Loss of anchorage to the substratum leads to a specific type of apoptosis in adherent cells, known as anoikis (37). To confirm anoikis induction, we assessed the expression levels of $\alpha$-SMA and $\beta 1$ integrin, a cell receptor subunit for collagen, fibronectin, and laminin. Rat and human HSCs express various types of integrins such as $\alpha_{1} \beta_{1}, \alpha_{2} \beta_{1}, \alpha_{5} \beta_{1}, \alpha_{\mathrm{v}} \beta_{1}, \alpha_{\mathrm{v}} \beta_{3}$ (vitronectin receptors), and $\alpha_{6} \beta_{4}$ (laminin receptor) (38). Because the $\beta 1$ integrin subunit is shared by four different integrins expressed on HSCs, its protein expression level was exam- ined. $\delta$-Tocopherol slightly and tocol significantly decreased $\alpha$-SMA and $\beta 1$ integrin expression. Decreased $\alpha$-SMA expression may affect the structural integrity of the cells required for substratum attachment. Loss of $\beta 1$ integrin may cause HSC detachment by disrupting its interaction with the substratum, and subsequently HSCs become susceptible to anoikis, which is similar to integrin antagonism with Gly-Arg-Gly-Asp-Ser peptideinduced apoptosis in HSCs (39). The mechanisms of integrin expression regulated by vitamin E must be understood because integrins are involved not only in anoikis/apoptosis but also in the migration and proliferation of adherent cells. This research may lead to the discovery of a new biological function of vitamin $\mathrm{E}$.

Our data revealed that $\delta$-tocopherol and tocol showed more potent antiproliferative and proapoptotic effects on activated HSCs than $\alpha$-tocopherol in vitro. $\delta$ Tocopherol and tocol did not show antiproliferative effects on primary hepatocytes and HepG2 cells. It is widely accepted that activated HSCs are principal contributors to liver fibrosis; thus, selective apoptosis induction in activated HSCs may provide an effective antifibrotic therapeutic strategy. We suggest that $\delta$ tocopherol and tocol may provide an effective antifibrotic therapeutic method by promoting the apoptosis in activated HSCs.

\section{Acknowledgments}

We wish to acknowledge the help of Professor Katsuyuki Murata, Akita University Graduate School of Medicine, in statistical analyses. We thank Dr. Kouichi Abe and Dr. Shunji Kasai, Vitamin E Information and Technology Section, Eisai Co. Ltd., for critical reading of the manuscript and helpful suggestions. This work was supported by Grants-in-Aid of the Ministry of Education, Culture, Sports, Science and Technology of Japan, and by Eisai Company Limited.

\section{REFERENCES}

1) Mustacich DJ, Bruno RS, Traber MG. 2007. Vitamin E. Vitam Horm 76: 1-21.

2) Freedman JE, Keaney JF Jr. 2001. Vitamin E inhibition of platelet aggregation is independent of antioxidant activity. J Nutr 131: 374S-377S.

3) Qureshi AA, Bradlow BA, Brace L, Manganello J, Peterson DM, Pearce BC, Manganello J, Peterson DM, Pearce BC, Wright JJ, Gapor A, Elson CE. 1995. Response of hypercholesterolemic subjects to administration of tocotrienols. Lipids 30: 1171-1177.

4) Tasinato A, Boscoboinik D, Bartoli GM, Maroni P, Azzi A. 1995. $d$ - $\alpha$-Tocopherol inhibition of vascular smooth muscle cell proliferation occurs at physiological concentrations, correlates with protein kinase $\mathrm{C}$ inhibition, and is independent of its antioxidant properties. Proc Natl Acad Sci USA 92: 12190-12194.

5) McCormick CC, Parker RS. 2004. The cytotoxicity of vitamin $\mathrm{E}$ is both vitamer- and cell-specific and involves a selectable trait. J Nutr 134: 3335-3342.

6) Traber MG, Packer L. 1995. Vitamin E: beyond antioxidant function. Am J Clin Nutr 62 (Suppl): 1501S1509S.

7) McIntyre BS, Briski KP, Gapor A, Sylvester PW. 2000. 
Antiproliferative and apoptotic effects of tocopherols and tocotrienols on preneoplastic and neoplastic mouse mammary epithelial cells. Proc Soc Exp Biol Med 224: 292-301.

8) Ni J, Pang ST, Yeh S. 2007. Differential retention of $\alpha$ vitamin $\mathrm{E}$ is correlated with its transporter gene expression and growth inhibition efficacy in prostate cancer cells. The Prostate 67: 463-471.

9) Sylvester PW. 2007. Vitamin E and apoptosis. Vitam Horm 76: 330-373.

10) Sario AD, Candelaresi C, Omenetti A, Benedetti A. 2007. Vitamin E in chronic liver diseases and liver fibrosis. Vitam Horm 76: 551-573.

11) Lewis JR, Mohanty SR. 2010. Nonalcoholic fatty liver disease: a review and update. Dig Dis Sci 55: 560-578.

12) Senoo H, Hata R, Nagai $Y$, Wake K. 1984. Stellate cells (vitamin A-storing cells) are the primary site of collagen synthesis in non-parenchymal cells in the liver. Biomed Res 5: 451-458.

13) Senoo H, Kojima N, Sato M. 2007. Vitamin A-storing cells (stellate cells). Vitam Horm 75: 131-159.

14) Friedman SL, Roll FJ, Boyles J, Bissell DM. 1985. Hepatic lipocytes: The principal collagen-producing cells of normal rat liver. Proc Natl Acad Sci USA 82: 8681-8685.

15) Friedman SL. 2007. Liver fibrosis: from mechanisms to treatment. Gastroenterol Clin Biol 31: 812-814.

16) Rockey DC, Boyles JK, Gabbiani G, Friedman SL. 1992. Rat hepatic lipocytes express smooth muscle actin upon activation in vivo and in culture. J Submicrosc Cytol Pathol 24: 193-203.

17) Knittel T, Shuppan D, Meyer-zum-Büshenfelde KH, Ramadori G. 1992. Differential expression of collagen types I, III, and IV by fat-storing (Ito) cells in vitro. Gastroenterology 102: 1724-1735.

18) Mukai K, Tokunaga A, Itoh S, Kanesaki Y, Ohara K, Nagaoka S, Abe K. 2007. Structure-activity relationship of the free-radical-scavenging reaction by vitamin $\mathrm{E}$ $(\alpha-, \beta-, \gamma-, \delta$-tocopherols) and ubiquinol-10: $\mathrm{pH}$ dependence of the reaction rates. J Phys Chem 11 1: 652-662.

19) Berry MN, Friend DS. 1969. High-yield preparation of isolated rat liver parenchymal cells: a biochemical and fine structural study. J Cell Biol 43: 506-520.

20) Seglen PO. 1976. Preparation of isolated rat liver cells. Methods Cell Biol 13: 29-83.

21) Senoo H, Hata R. 1993. Isolation of perisinusoidal stellate cells (vitamin A-storing cells, fat-storing cells) of the rat liver. Connect Tissue 25: 129-137.

22) Vanhaecke T, De Smet K, Beken S, Pauwels M, Vercruysse A, Rogiers V. 1998. Rat heptatocyte culturesconventional monolayer cultures and cocultures with rat liver epithelial cells. Methods Mol Biol 107: 311317.

23) Peters SJ, Vanhaecke T, Papeleu P, Rogiers V, Haagsman HP, van Norren K. 2010. Co-culture of primary rat hepatocytes with rat liver epithelial cells enhances interleukin-6-induced acute-phase protein response. Cell Tissue Res 340: 451-457.

24) Vogel S, Piantedosi R, Frank J, Lalazar A, Rockey DC, Friedman SL, Blaner WS. 2000. An immortalized rat liver stellate cell line (HSC-T6): a new cell model for the study of retinoid metabolism in vitro. J Lipid Res $\mathbf{4 1}$ : 882-893.

25) Green LM, Reade JL, Ware CF. 1984. Rapid colorimetric assay for cell viability: application to the quantitation of cytotoxic and growth inhibitory lymphokines. I Іттиnol Method 70: 257-268.

26) Kim KA, Lim YS, Kim KM, Yoon JH, Lee HS. 2005. 15dDeoxy-Delta12,14-prostaglandin J2 modulates collagen type I synthesis in human hepatic stellate cells by inducing oxidative stress. Prostaglandins Leukot Essent Fatty Acids 73: 361-367.

27) Yamaguchi N, Kimura S, McBride OW, Hori H, Yamada Y, Kanamori T, Yamakoshi H, Nagai Y. 1992. Molecular cloning and partial characterization of a novel collagen chain, alpha $1(\mathrm{XVI})$, consisting of repetitive collagenous domains and cysteine-containing non-collagenous segments. J Biochem 112: 856-863.

28) Gueguen S, Leroy P, Gueguen R, Siest G, Visvikis S, Herbeth B. 2005. Genetic and environmental contributions to serum retinol and $\alpha$-tocopherol concentrations: the Stanislas Family Study. Am J Clin Nutr 81: 1034-1044.

29) Kempná P, Reiter E, Arock M, Azzi A, Zingg JM. 2004. Inhibition of HMC-1 mast cell proliferation by vitamin E. Involvement of the protein kinase B pathway. J Biol Chem 279: 50700-50709.

30) Yoshida Y, Saito Y, Jones LS, Shigeri Y. 2007. Chemical reactivities and physical effects in comparison between tocopherols and tocotrienols: physiological significance and prospects as antioxidants. J Biosci Bioeng 104: 439-445.

31) Wu D, Meydani M, Beharka AA, Serafini M, Martin KR, Meydani SN. 2000. In vitro supplementation with different tocopherol homologues can affect the function of immune cells in old mice. Free Radic Biol Med 28: 643651.

32) Tsuzuki W, Yunoki R, Yoshimura H. 2007. Intestinal epithelial cells absorb $\gamma$-tocotrienol faster than $\alpha$-tocopherol. Lipids 42: 163-170.

33) Schneiderhan W, Schmid-Kotsas A, Zhao J, Grünert A, Nüssler A, Weidenbach H, Menke A, Schmid RM, Adler G, Bachem MG. 2001. Oxidized low-density lipoproteins bind to the scavenger receptor, $\mathrm{CD} 36$, of hepatic stellate cells and stimulate extracellular matrix synthesis. Нераtology 34: 729-737.

34) Kang Q, Chen A. 2009. Curcumin suppresses expression of low-density lipoprotein (LDL) receptor, leading to the inhibition of LDL-induced activation of hepatic stellate cells. Br J Pharmacol 157: 1354-1367.

35) Mardones P, Rigotti A. 2004. Cellular mechanisms of vitamin E uptake: relevance in $\alpha$-tocopherol metabolism and potential implications for disease. J Nutr Biochem 15: 252-260.

36) Shichiri M, Takanezawa Y, Rotzoll DE, Yoshida Y, Kokubu T, Ueda K, Tamai H, Arai H. 2010. ATP-binding cassette transporter A1 is involved in hepatic $\alpha$-tocopherol secretion. J Nutr Biochem 21: 451-456.

37) Chiarugi P, Giannoni E. 2008. Anoikis: A necessary death program for anchorage-dependent cells. Biochem Pharmacol 76: 1352-1364.

38) Carloni V, Romanelli RG, Pinzani M, Laffi G, Gentilini P. 1996. Expression and function of integrin receptors for collagen and laminin in cultured human hepatic stellate cells. Gastroenterology 110: 1127-1136.

39) Iwamoto H, Sakai H, Tada S, Nakamuta M, Nawata H. 1999. Induction of apoptosis in rat hepatic stellate cells by disruption of integrin-mediated cell adhesion. J Lab Clin Med 134: 83-89. 